\title{
Estimation of yield and grain qualities of marker assisted backcross derived lines of submergence rice against sheath blight disease
}

\author{
S. K. Ghritlahre ${ }^{2}$, Mahesh Rao ${ }^{4}$, S. L. Pavani ${ }^{3}$, Vineeta Singh ${ }^{3}$, U. S. Singh ${ }^{5}$, Sandhya ${ }^{1}$ and \\ P. K. Singh ${ }^{1^{*}}$ \\ ${ }^{1}$ Department of Genetics and Plant Breeding, Institute of Agricultural Sciences, Banaras Hindu University, \\ Varanasi, INDIA \\ ${ }^{2}$ Current address: Crop Improvement Division, National Rice Research Institute, Cuttack, (Odisha), INDIA \\ ${ }^{3}$ Department Mycology and Plant Pathology, Institute of Agricultural Science, Banaras Hindu University, Varanasi, \\ INDIA \\ ${ }^{4}$ National Research Center on Plant Biotechnology, Pusa Campus, New Delhi, INDIA \\ ${ }^{5}$ International Rice Research Institute-Stress Tolerant Rice for Africa and South Asia, India Office, Rajendra Place, \\ New Delhi, INDIA \\ *Corresponding author. E-mail: pksbhu@gmail.com
}

Received: October 6, 2016; Revised received: February 14, 2017; Accepted: May 9, 2017

\begin{abstract}
Sheath blight caused by Rhizoctonia solani is one of the most devastating diseases of rice (Oryza sativa) and causes enormous yield losses over the world after blast, the disease can cause yield loss upto 50 per cent in advanced stage and adversely affects quality of straw. Breeding for resistant varieties is the only viable option to combat the disease efficiently. In this study, our findings showed a significant increase in number of spikelet's per panicle $(3.45 \%)$, test weight $(0.62 \%)$ and grain yield $(0.72 \%)$ compared to recurrent parent Swarna sub-1. The range of mean performance of $18 \mathrm{BC}_{2} \mathrm{~F}_{1}$ selected improved lines varied for per cent disease severity from 26.75 to 43.58 at 16 days after inoculation. Among the 18 improved lines, only four lines (Swarna sub-1-6, Swarna sub-1-32, Swarna sub-1-13 and Swarna sub-1-29) showed resistance score of 1-3. The remaining fourteen lines showed moderate resistance with a score of $3-5$. Hence, the resistance line could be exploited in sheath blight resistance breeding programme and the same line can also be released as a variety against sheath blight of rice after testing over multilocation trails.
\end{abstract}

Keywords: Per cent disease severity, Sheath blight, Rice, Yield per plant

\section{INTRODUCTION}

Soil borne pathogen Rhizoctonia solani is endemic to areas where temperature and relative humidity are high and reduced yield upto 54.3 per cent in advanced stage and also adversely affects quality of straw (Chahal et al., 2003; Savary et al., 2006). Losses depend on the growth stage of plant at which infection occurs, level of resistance in a particular genotype and prevailing environmental conditions (Joshi et al., 2016). Rice is India's pre-eminent crop, and is the vital food for people in the eastern and southern parts of the country (Ghritlahre et al., 2016). Though its productivity fluctuates significantly from region to region; season to season due to various biotic factors such as pest and diseases. Rice genetic resources have not been comprehensively exploited for improvement of sheath blight resistance, although many cultivars and lines have been reported as promising sources of resistance (Srinivasachary et al., 2011). The host resistance is the most economical and environmentally sound strategy in managing sheath blight, but substantial differences in the levels of susceptibility to the sheath blight pathogen among rice cultivars have been observed under field conditions. Sheath blight resistance is believed to be controlled by polygenic quantitative trait loci (QTLs)). Li et al., (1995) first identified Sheath blightQTLs using restricted fragment length polymorphism (RFLP) markers and field evaluations. Subsequently, a number of QTLs (around 50 QTLs) associated with sheath blight resistance have been reported spanning over all 12 chromosomes in cultivated varieties, deepwater varieties and wild species (Jia et al., 2009; Zuo et al., 2010; Wang et al., 2012; Xu et al., 2010) by using segregating $\mathrm{F}_{2}$ populations, double haploid $(\mathrm{DH})$, and recombinant inbred line (RIL) populations under field conditions, although the mechanisms of resistance of these QTLs are poorly understood. Among these, $q S B R 11-1$ is a major QTL that has been found to be effective against the sheath blight pathogen consistently over time and at different locations (Channamallikarjuna et al., 2010). 'Tetep', an indica rice cultivar from Vietnam, is the source of resistance 


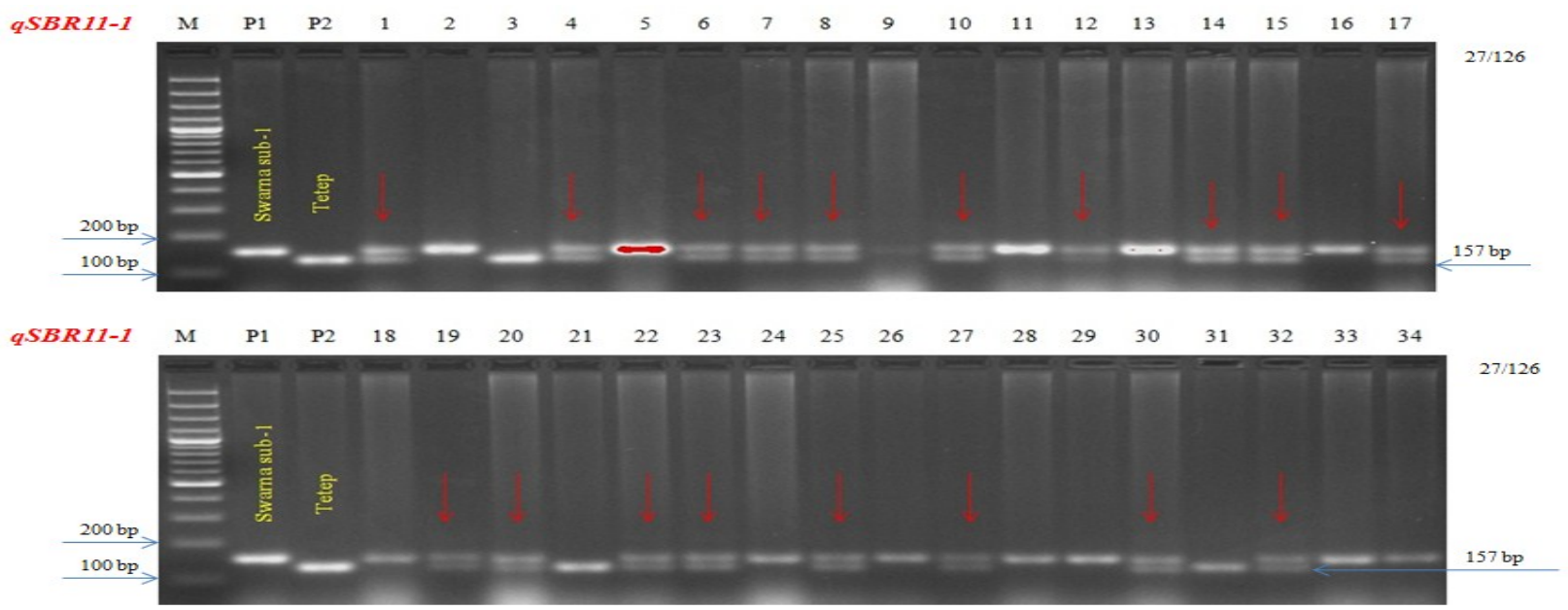

Plate 1. Foreground selection for sheath blight disease resistance QTL/genes qSBR11-1 in $B C_{1} F_{1}$ generations. Where $P_{1}$ is recurrent parent, $P_{2}$ is donor parent and $M$ is 100 bp DNA size markers.

to both blast (Pi54) and sheath blight (qSBR11-1) diseases. In addition, 'Tetep' is an invaluable donor of several other resistance genes for blast resistance (Singh et al., 2012); and 10 other QTLs for sheath blight resistance (Channamallikarjuna et al., 2010).

Marker-assisted backcross breeding (MABB) coupled with phenotypic selection for agronomic, grain quality traits has been used to incorporate sheath blight resistance QTL qSBR11-1 into 'Improved Pusa Basmati 1' (Singh et al.,2012a) and QTLs qSBR11-1, qSBR112 and qSBR7-1 into 'Pusa 6B' CMS line (Singh et al., 2015). In our study, in order to incorporate of ShB disease resistance QTL qSBR11-1 into Swarna sub-1, a backcross approach was used in which backcross was restricted to two generations and foreground and background marker assisted selection was also done at the early segregating generations such as $\mathrm{BC}_{1} \mathrm{~F}_{1}$ and $\mathrm{BC}_{2} \mathrm{~F}_{1}$. Further, the generations were handled as in pedigree model.

\section{MATERIALS AND METHODS}

Plant material: Swarna sub-1, submergence tolerance variety, was used as the recurrent parent in the present study. Tetep, a Vietnamese indica rice variety has been used as the donor for the sheath blight resistance QTLs, qSBR11-1. Tetep was crossed with Swarna sub1 ; and the single $\mathrm{F}_{1}$ plant was backcrossed with Swarna sub-1, to generate the $\mathrm{BC}_{1} \mathrm{~F}_{1}$. Marker assisted foreground selection among $\mathrm{BC}_{1} \mathrm{~F}_{1}$ plants initially targeted the SSR marker RM224 linked for qSBR111 were done which was coupled with selection for phenotypic similarity with the recurrent parent. Selected plants that were heterozygous for RM224 marker were further backcrossed with Swarna sub-1 to generate $\mathrm{BC}_{2} \mathrm{~F}_{1}$. Among $\mathrm{BC}_{2} \mathrm{~F}_{1}$ plants were again marker assisted foreground selection with SSR marker RM224 linked for qSBR11-1 done which was coupled with selection for phenotypic similarity with the recurrent parent. Selected plants that were heterozygous for
RM224 marker in $\mathrm{BC}_{2} \mathrm{~F}_{1}$ generation were artificially screened against Rhizoctonia solani and the resistant lines were subjected for qualitative and quantitative traits estimation.

Molecular marker analysis: Total genomic DNA was extracted by the micro-extraction protocol of Prabhu et al., (1998). Polymerase chain reaction (PCR) was performed in a thermal cycler (G-Storm, Somerset, UK) using a $10 \mathrm{~mL}$ total reaction volume as described previously (Basavaraj et al., 2010). This contained $30 \mathrm{ng}$ mL21 of template DNA, 5 pmol of each primer (synthesized from Sigma Inc., St. Louis, MO, USA), $1.5 \mathrm{mM} \mathrm{MgCl} 2,0.2 \mathrm{mM}$ dNTPs (MBI, Fermentas, Vilnius, Lithuania) and $0.5 \mathrm{U}$ of Taq polymerase (Bangalore Genei, Bangalore, Karnataka, India). Polymerase chain reaction comprised one cycle of denaturation at $958 \mathrm{C}$ for $5 \mathrm{~min}$, followed by 35 cycles at 95 $8 \mathrm{C}$ for $30 \mathrm{~s}, 558 \mathrm{C}$ for $30 \mathrm{~s}$ and $728 \mathrm{C}$ for $1 \mathrm{~min}$, with a final extension of $728 \mathrm{C}$ for $7 \mathrm{~min}$. The amplified products were resolved on $3.5 \%$ MetaphorTM gel (Lonza, Rockland, ME, USA) containing 0.1 mgmL21 of ethidium bromide (Amresco, Solon, OH, USA) along with a DNA size standard ladder (MBI, Fermentas) and documented in a Gel Documentation System (Biorad, Hercules, CA, USA).

Screening for sheath blight resistance: The screening for sheath blight resistance in the backcross derived lines was carried out through artificial inoculation under field conditions at the experimental farm of the Institute of Agricultural Sciences, Banaras Hindu University, Varanasi, India. A virulent isolate of $R$. solani was obtained from Indian Institute of Rice Research, Hyderabad (wild type strain-Rajendranagar). The inoculum of isolate was multiplied following the procedure described by Bhaktavatsalam et al. (1978). Shoots of water sedge (Typha angustata) were cut into pieces of 4-5 cm long washed thoroughly and soaked in Typha medium (peptone: $10.0 \mathrm{~g}$, Sucrose: $20 \mathrm{~g}, \mathrm{~K}_{2} \mathrm{HPO}_{4}$ : $0.1 \mathrm{~g}, \mathrm{MgSO}_{4}: 0.1 \mathrm{~g}$, Distilled water: $1 \mathrm{~L}$ ) for $5 \mathrm{~min}$. 


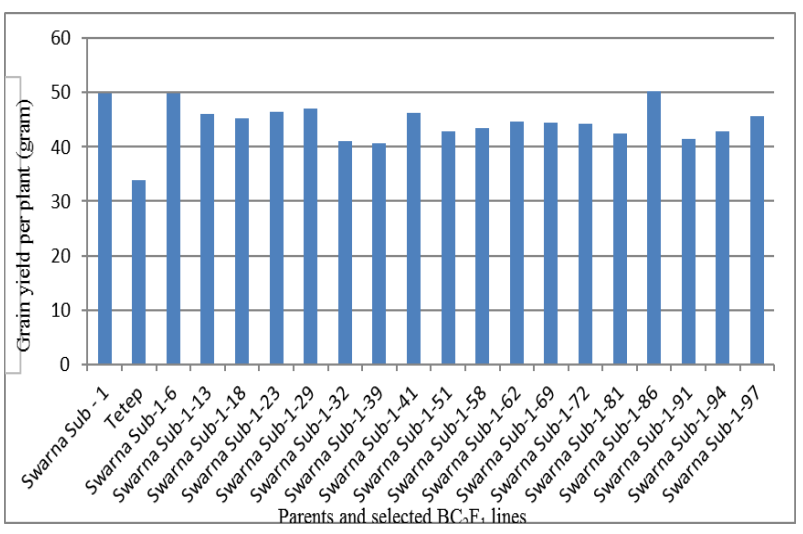

Fig. 1. Mean performance of grain yield per plant of parents and $18 \mathrm{BC}_{2} \mathrm{~F}_{1}$ selected backcross derived lines.

The pieces were drained for excess water and later these were filled loosely to one third volume of $250 \mathrm{ml}$ conical flask and sterilize in autoclaved at $1.05 \mathrm{~kg} /$ $\mathrm{cm}^{2}$ for $20 \mathrm{~min}$ each for two consecutive days. The sterilized typha flask was inoculated with $5 \mathrm{~mm}$ diameter disc of actively growing mycelium of the isolate and incubated for 15 days at $28 \pm 2{ }^{\circ} \mathrm{C}$. These colonized typha pieces were used as inoculum.Plants were inoculated at the maximum tillering stage (30-35 days after sowing) with colonized typha pieces. Two pieces of typha were placed between tillers in the central region of rice hills, just above the water level. Water level (5$10 \mathrm{~cm}$ ) was maintained constantly for ensuring enough humidity to promote disease development. The inoculated plants were regularly examined for appearance of symptoms starting from 48 hours after inoculation and number of lesions and their length on the rice sheath around the inoculation point will be recorded from 96 hours after inoculation. The data on disease intensity was recorded on four different dates at four day intervals i.e. $4^{\text {th }}, 8^{\text {th }}, 12^{\text {th }}$, and $16^{\text {th }}$ day after inoculation (Kumar et al., 2008).

$\mathrm{PDI}=($ Sum of all ratings $\times 100) /($ Total number of observations $\times$ Maximum rating scale)

$$
A U D P C=\sum_{i=1}^{n-1}\left\{\left[\left(X_{i+1}+X_{i}\right) / 2\right] * \quad\left(\mathrm{t}_{\mathrm{i}+1}-\mathrm{t}_{\mathrm{i}}\right)\right\}
$$

Where;

$\mathrm{X}_{\mathrm{i}}$ is the disease index expressed as a proportion at the $i^{\text {th }}$ observation.

$t_{i}$ is the time (days after planting) at the $i^{\text {th }}$ observations and

$\mathrm{n}$ is the total number of observations.

Evaluation of quantitative and qualitative traits for statistical analysis: The derived lines in $\mathrm{BC}_{2} \mathrm{~F}_{1}$ generation together with parental lines were evaluated for quantitative and qualitative traits performance in a randomized complete block design with three replications with $20 \times 15 \mathrm{~cm}$ spacing at the experimental farm of Institute of Agricultural Sciences, BHU, Varanasi during Kharif 2013. The data of 10 plants were recorded for various quantitative traits such as number of reproductive tillers per plant (NRT), plant height $(\mathrm{PH})$,

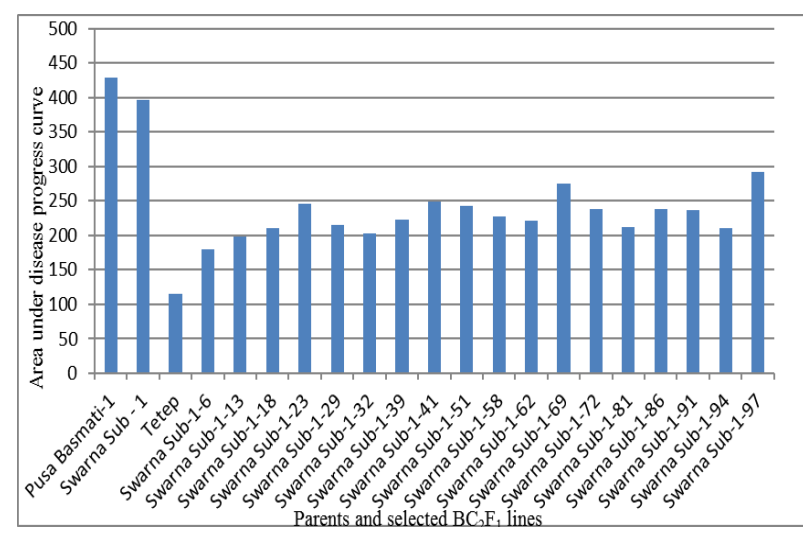

Fig. 2. Mean performance of area under disease progress curve of parents and $23 \mathrm{BC}_{2} F_{1}$ selected backcross derived lines.

days to maturity (DM), days to heading (DH), panicle length (PL), Weight of panicle (WP), number of spikelet's per panicle (SP), test weight (TW) and yield per plant (YP) using the standard evaluation system of rice (IRRI 2002). The qualitative traits (grain quality) were determined by length/breath before cooking (L/B ratio $\mathrm{BC})$, length/breath after cooking (L/B ratio AC), Amylose content (AC), gel consistency (GC) and gelatinization temperature (GT) (Gopalakrishnan et al., 2008).

\section{RESULTS AND DISCUSSION}

\section{MAS for QTLs governing sheath blight resistance:} In the present study, $77 \mathrm{~F}_{1}$ plants were raised from a cross (Swarna sub-1 $\times$ Tetep) and their leaf samples were taken at 21 days after transplanting, DNA was isolated from these samples and each and every plant was tagged. Foreground selection was done with RM 224 primer for qSBR11-1 QTL linked with sheath blight resistant. The 68 plants showed presence of qSBR11-1QTL in the $\mathrm{F}_{1}$ plants while remaining 9 plants showed bands corresponding to recurrent parent indicating they were selfed. All 68 plants that contained qSBR11-1 QTL/gene, showed the 10-15 days earlier maturity than the recurrent parent Swarna sub1. It means all $68 \mathrm{~F}_{1}$ plants had $q S B R 11-1 \mathrm{QTL} / \mathrm{gene}$ bands from the donor parent (Tetep). The plant characters of Swarna sub-1 and Tetep were distinctly different and the true $F_{1}$ plants were easily recognised. Out of $68 \mathrm{~F}_{1}$ plants, only $17 \mathrm{~F}_{1}$ plants were exactly similar to their recurrent parent Swarna sub-1 and these were tagged and backcrossed with Swarna sub-1 to produced $\mathrm{BC}_{1} \mathrm{~F}_{1}$ seeds.

The $126 \mathrm{BC}_{1} \mathrm{~F}_{1}$ seeds were sown to raise $\mathrm{BC}_{1} \mathrm{~F}_{1}$ generation and each and every plant was tagged at seedling stage. Again marker assisted selection has been applied for the foreground selection among $126 \mathrm{BC}_{1} \mathrm{~F}_{1}$ plants. Out of them, only 27 plants showed positive bands for QTLqSBR11-1, while remaining plants carried the negative QTL/gene to the marker RM224 (Plate 1). The resistance of these 27 plants were also confirmed by exposing them to disease inoculation with Rhi- 
zoctonia solani strain $R$. nagar wild type. The per cent disease severity of these 27 plants were significantly lesser than the recurrent parent Swarna sub-1 as well as susceptible check Pusa Basmati-1 (PB-1), while closer to the resistance parent Tetep as these plants had resistance QTLqSBR 11-1. Out of 27 plants, only 9 $\mathrm{BC}_{1} \mathrm{~F}_{1}$ plants were exactly similar to recurrent parent Swarna sub-1carring the resistant QTL/gene and these were backcrossed with Swarna sub-1 to produced $\mathrm{BC}_{2} \mathrm{~F}_{1}$ seeds. The $93 \mathrm{BC}_{2} \mathrm{~F}_{1}$ generation seed sown, each and every plant was tagged further foreground selection for the sheath blight resistant QTL/gene qSBR11-1. On the basis of foreground selection, among $93 \quad \mathrm{BC}_{2} \mathrm{~F}_{1}$ plants, only 32 plants showed qSBR11-1 QTL. The 32 plants showed the QTL/gene for resistance and among them only 18 plants were phenotypically similar to recurrent parent in respect to morphological traits. Therefore, only 18 plants (selected backcross derived lines) subjected for quantitativeand qualitativetraits estimation.

Evaluation for disease resistance of improved Swarna sub-1 lines: Evaluation of Swarna sub-1 and Tetep along with the improved Swarna sub-1 lines for sheath blight resistance confirmed susceptible reaction of Swarna sub-1 tohighly virulent isolate $R$. nagar wild type under field conditions, Tetep showed resistance with a score of 1-3 and the recurrent parent Swarna sub-1 showed susceptible reaction with score of 5-7. Among the 18 improved lines, only four lines (Swarna sub-1-6, Swarna sub-1-32, Swarna sub-1-13 and Swarna sub-1-29) showed resistance score of 1-3. The remaining fourteen lines showed moderate resistance with a score of 3-5. Overall, two improved
Swarna sub-1 lines (Swarna sub-1-6 and Swarna sub-132) advanced for further generation.

Agronomic performance of selected backcross derived lines for quantitative traits: The agronomic performance for 9 quantitative traits of parents and selected $18 \mathrm{BC}_{2} \mathrm{~F}_{1}$ backcross derived lines showed that most of the agronomic traits were similar to the recurrent parent (Table 1). The number of reproductive tillers of the selected $18 \mathrm{BC}_{2} \mathrm{~F}_{1}$ linesranged from 9.0 to 15.0 with an average of 12 similar to that of Swarna sub-1. The average plant height was $98.33 \mathrm{~cm}$ and with a range of 91.33-105.33.1 cm similar to that of Swarna sub-1 $(98.00 \mathrm{~cm})$. The days to heading ranged from 94.0 to 98.0 days with an average of 96 days which was lesser than Swarna sub-1 (102 days). Similarly, the days to maturity ranged from 130.0 to 138.0 days with an average of 134 days lesser than recurrent parent (140 days). However, the maximum panicle weight of 4.38 was observed in Swarna sub-1-62 which was higher than Swarna sub-1(4.10). Similarly, number of spikelets per panicle (S/P) and test weight (TW) of some of the backcross derived lines (232 S/Pand 230S/ $\mathrm{P}$ in Swarna sub-1-81and Swarna sub-1-18) and TW of $19.25 \mathrm{~g}$ and $19.24 \mathrm{~g}$ in Swarna sub-1-18 and Swarna sub-1-72) were better that of Swarna sub-1 (S/P224 and TW $19.13 \mathrm{~g}$ ). The grain yield per plant ranged from $39.98 \mathrm{~g}$ to $50.17 \mathrm{~g}$ with anaverage of $45.8 \mathrm{~g}$ which was lower than Swarna sub-1 (49.81 g). However, the maximum grain yield per plant of $50.17 \mathrm{~g}$ was observed in Swarna sub-1-86 which was higher than Swarna sub-1(49.81 g). Mean performance of grain yield per plant of parents and $18 \mathrm{BC}_{2} \mathrm{~F}_{1}$ selected back-

Table 1. Mean performance for 9 quantitative traits of parents and $18 \mathrm{BC}_{2} \mathrm{~F}_{1}$ selected backcross derived lines.

\begin{tabular}{|c|c|c|c|c|c|c|c|c|c|}
\hline Lines number & NRT & PH & DM & DH & PL & PW & $\mathbf{S} / \mathbf{P}$ & TW & $\mathbf{Y} / \mathbf{P}$ \\
\hline Swarna Sub - 1 & 13 & 96.00 & 140 & 102 & 27.00 & 4.10 & 223.67 & 19.13 & 49.81 \\
\hline Tetep & 7 & 129.67 & 104 & 72 & 25.38 & 3.71 & 165.67 & 21.56 & 33.85 \\
\hline Swarna Sub-1-6 & 13 & 101.33 & 131 & 97 & 27.05 & 4.20 & 218.33 & 18.84 & 49.78 \\
\hline Swarna Sub-1-13 & 11 & 99.33 & 132 & 97 & 26.30 & 3.83 & 202.67 & 18.92 & 46.09 \\
\hline Swarna Sub-1-18 & 13 & 100.33 & 135 & 98 & 25.85 & 4.13 & 230.00 & 19.25 & 45.33 \\
\hline Swarna Sub-1-23 & 14 & 103.67 & 130 & 95 & 22.02 & 3.96 & 190.67 & 18.80 & 46.49 \\
\hline Swarna Sub-1-29 & 15 & 100.00 & 137 & 96 & 26.97 & 4.19 & 211.67 & 19.08 & 47.08 \\
\hline Swarna Sub-1-32 & 11 & 105.33 & 136 & 98 & 23.03 & 3.74 & 216.67 & 19.1 & 41.05 \\
\hline Swarna Sub-1-39 & 9 & 103.00 & 131 & 96 & 26.67 & 3.93 & 209.33 & 18.69 & 40.62 \\
\hline Swarna Sub-1-41 & 14 & 105.33 & 132 & 94 & 25.20 & 4.22 & 188.61 & 19.09 & 46.17 \\
\hline Swarna Sub-1-51 & 11 & 103.00 & 138 & 97 & 24.04 & 3.87 & 216.67 & 19.16 & 42.78 \\
\hline Swarna Sub-1-58 & 10 & 102.00 & 136 & 97 & 24.29 & 3.88 & 216.00 & 19.02 & 43.39 \\
\hline Swarna Sub-1-62 & 11 & 104.67 & 132 & 94 & 22.26 & 4.38 & 206.00 & 18.97 & 44.60 \\
\hline Swarna Sub-1-69 & 12 & 103.33 & 130 & 95 & 25.42 & 3.75 & 207.33 & 19.10 & 44.51 \\
\hline Swarna Sub-1-72 & 13 & 104.67 & 132 & 95 & 25.63 & 3.77 & 205.33 & 19.24 & 44.34 \\
\hline Swarna Sub-1-81 & 10 & 103.33 & 134 & 96 & 26.45 & 4.16 & 231.67 & 18.91 & 42.49 \\
\hline Swarna Sub-1-86 & 15 & 101.67 & 134 & 97 & 24.84 & 3.77 & 226.00 & 19.12 & 50.17 \\
\hline Swarna Sub-1-91 & 13 & 103.67 & 131 & 94 & 26.00 & 4.23 & 213.67 & 18.9 & 41.53 \\
\hline Swarna Sub-1-94 & 9 & 102.33 & 135 & 97 & 26.14 & 3.85 & 209.33 & 18.9 & 42.79 \\
\hline Swarna Sub-1-97 & 12 & 104.67 & 136 & 98 & 25.82 & 3.80 & 190.33 & 19.16 & 45.74 \\
\hline SE & 1.85 & 3.09 & 0.99 & 0.75 & 1.86 & 0.28 & 17.56 & 0.1 & 4.24 \\
\hline SD & 1.97 & 6.49 & 7.32 & 5.71 & 1.50 & 0.21 & 15.87 & 0.59 & 3.75 \\
\hline
\end{tabular}

NRT- Number of reproductive tillers per plant, PH-Plant height, DM-Days to maturity, DH-Days to heading, PL-Panicle length, PW-Panicle weight, S/P-Total no of spikelet per panicle, TW-Test weight, Y/P-Yield per plant 
cross derived lines are presented in Fig 1. The spikelet's per panicle, test weight and grain yield were increased up to $3.45 \%, 0.62 \%$ and $0.72 \%$, in Swarna sub-1-81, Swarna sub-1-18 and Swarna sub-1-86 respectively over recurrent parent Swarna sub-1.

Agronomic performance of selected backcross derived lines for qualitative traits (grain quality), disease severity and AUDPC: The grain quality of selected backcross derived lines (Table 2) showed that all of them were almost similar in grain and cooking quality with that of the recurrent parent. The length/ breadth ratio before cooking (L/B Ratio $\mathrm{BC}$ ) ranged from $2.66 \mathrm{~mm}$ to $2.74 \mathrm{~mm}$ as against $2.66 \mathrm{~mm}$ of Swarna sub-1, while the length/breadth ratio after cooking (L/B Ratio AC) of the backcross derived lines ranged from $2.81 \mathrm{~mm}$ to $2.90 \mathrm{~mm}$ for which Swarna sub-1 recorded an average of $2.87 \mathrm{~mm}$. The average amylase content (AC) was $29.91 \%$ and with a range of $28.70-31.11 \%$ slightly higher to that of Swarna sub-1 $(27.69 \%)$. All of the selected backcross derived lines was found to have an ASV score of 2 and gel consistency (GC) ranged from $125.67 \mathrm{~mm}$ to $129.68 \mathrm{~mm}$ with an average of $127.68 \mathrm{~mm}$ similar to that of Swarna sub-1. The per cent disease severity ranged from 26.75 to $43.58 \%$ with an average of $35.17 \%$ which was significantly lower than the recurrent parent $(59.43 \%)$ at 16 days after inoculation. The areas under disease progress curve (AUDPC) of parents, susceptible check (PB-1) and $18 \mathrm{BC}_{2} \mathrm{~F}_{1}$ selected backcross derived lines are presented in Fig 2. The AUDPCranged from 179.22 to 292.24 with an average of 235.73 which was significantly lower than the recurrent parent (395.87).

Marker assisted selection (MAS) has been proved to be an efficient selection tool for those traits that are difficult and expensive to evaluate in a shorter time period (Tanksley et al., 1989) such as rice blast and sheath blight resistance owing to its advantages of ease and precision in selection of target traits even before their expression. MAS coupled with stringent phenotypic selection can provide rich dividends in breeding success (Collard and Mackill, 2008). Marker assisted backcross breeding (MABB) is widely demonstrated to be the most effective way of transferring specific gene(s)/QTLs into rice varieties/parental lines of hybrids such as resistance to sheath blight (Singh et al.,2012b). Introgression of major resistant QTL/genes in a single variety and the use of varietal mixtures with different resistance QTL/genes are suggested as way to prevent or delay the breakdown of resistance.

The sheath blight disease is managed agronomically by the use of chemical agents (Jia et al., 2009). Development of sheath blight resistance cultivars remained elusive by conventional approaches because, identification of complete sheath blight resistance was difficult due to conditioning of the resistance by quantitative genes (Zuo et al., 2008). Recently, eight QTLs for sheath blight resistance were mapped on six chromosomes such as $1,3,7,8,9$ and 11 in the genotype Tetep using QTL mapping strategy

Table 2. Mean performance for 4 qualitative traits, disease severity and AUDPC of parents and $18 \mathrm{BC}_{2} \mathrm{~F}_{1}$ selected backcross derived lines.

\begin{tabular}{|c|c|c|c|c|c|c|c|c|c|}
\hline \multirow[b]{2}{*}{ Lines number } & \multirow{2}{*}{$\begin{array}{l}\text { Kernal L/B } \\
\text { Ratio Before } \\
\text { cooking }(\mathrm{mm})\end{array}$} & \multirow{2}{*}{$\begin{array}{lr}\text { Kernal } & \mathrm{L} / \mathrm{B} \\
\text { Ratio } & \text { after } \\
\text { cooking }(\mathrm{mm})\end{array}$} & \multirow[b]{2}{*}{$\begin{array}{l}\mathrm{AC} \\
(\%)\end{array}$} & \multirow[b]{2}{*}{ GC } & \multicolumn{4}{|c|}{ Disease severity (\%) } & \multirow[b]{2}{*}{ AUDPC } \\
\hline & & & & & 4 DAI & 8 DAI & $12 \mathrm{DAI}$ & $16 \mathrm{DAI}$ & \\
\hline Pusa Basmati-1 & - & - & - & - & 8.79 & 28.18 & 41.50 & 66.41 & 429.16 \\
\hline Swarna Sub - 1 & 2.66 & 2.87 & 27.69 & 129.18 & 8.89 & 26.70 & 38.11 & 59.43 & 395.87 \\
\hline Tetep & 2.84 & 3.01 & 33.53 & 121.26 & 4.47 & 7.24 & 10.56 & 17.85 & 115.83 \\
\hline Swarna Sub-1-6 & 2.71 & 2.89 & 28.92 & 126.37 & 6.28 & 9.49 & 18.80 & 26.75 & 179.22 \\
\hline Swarna Sub-1-13 & 2.70 & 2.81 & 29.33 & 127.66 & 5.54 & 9.81 & 22.16 & 29.25 & 197.48 \\
\hline Swarna Sub-1-18 & 2.73 & 2.90 & 29.06 & 127.98 & 4.77 & 10.49 & 23.53 & 32.22 & 210.05 \\
\hline Swarna Sub-1-23 & 2.66 & 2.84 & 29.03 & 129.25 & 6.75 & 15.39 & 26.14 & 32.89 & 245.43 \\
\hline Swarna Sub-1-29 & 2.73 & 2.90 & 29.88 & 126.55 & 5.41 & 14.59 & 21.85 & 29.37 & 215.32 \\
\hline Swarna Sub-1-32 & 2.68 & 2.85 & 28.81 & 128.36 & 5.64 & 13.65 & 20.41 & 27.64 & 202.81 \\
\hline Swarna Sub-1-39 & 2.72 & 2.89 & 28.77 & 129.41 & 4.62 & 14.74 & 22.92 & 31.43 & 222.73 \\
\hline Swarna Sub-1-41 & 2.72 & 2.89 & 28.73 & 128.31 & 5.25 & 16.27 & 24.52 & 37.54 & 248.73 \\
\hline Swarna Sub-1-51 & 2.74 & 2.90 & 28.70 & 127.55 & 5.22 & 15.50 & 25.66 & 33.49 & 242.07 \\
\hline Swarna Sub-1-58 & 2.67 & 2.84 & 28.72 & 126.55 & 5.72 & 14.56 & 23.25 & 32.52 & 227.70 \\
\hline Swarna Sub-1-62 & 2.73 & 2.90 & 28.78 & 129.68 & 5.57 & 14.69 & 22.51 & 30.46 & 220.85 \\
\hline Swarna Sub-1-69 & 2.74 & 2.90 & 31.11 & 125.67 & 5.52 & 17.12 & 27.14 & 43.58 & 275.25 \\
\hline Swarna Sub-1-72 & 2.73 & 2.90 & 28.83 & 126.51 & 5.54 & 14.53 & 25.07 & 34.55 & 238.60 \\
\hline Swarna Sub-1-81 & 2.73 & 2.90 & 28.73 & 127.54 & 4.74 & 14.96 & 20.05 & 30.92 & 211.35 \\
\hline Swarna Sub-1-86 & 2.70 & 2.86 & 29.05 & 128.50 & 4.78 & 14.48 & 24.51 & 36.34 & 238.19 \\
\hline Swarna Sub-1-91 & 2.72 & 2.89 & 28.80 & 129.00 & 5.93 & 14.73 & 25.24 & 32.40 & 236.55 \\
\hline Swarna Sub-1-94 & 2.70 & 2.86 & 28.74 & 127.99 & 4.77 & 12.65 & 21.21 & 32.39 & 209.75 \\
\hline Swarna Sub-1-97 & 2.72 & 2.88 & 30.22 & 125.89 & 6.00 & 19.88 & 29.42 & 41.53 & 292.24 \\
\hline SE & 0.02 & 0.02 & 0.18 & 0.28 & 0.44 & 0.73 & 1.26 & 2.11 & 13.06 \\
\hline SD & 0.04 & 0.04 & 1.22 & 1.90 & 1.19 & 4.93 & 6.35 & 10.66 & 67.28 \\
\hline
\end{tabular}

AC- Amylose content, GC-Gel consistency, AUDPC-Area Under Disease Progress Curve 
(Channamallikarjuna et al., 2010). Singh et al., (2015) validated all the eight QTLs using respective tightly linked peak markers and had chosen three QTLs (qSBR11-1, qSBR11-2 and qSBR7-1) for introgression into Pusa 6B line. Among these QTLs, qSBR11-1 was mapped across two locations and seasons and qSBR7-1 was mapped under two locations, while qSBR11-2 was detected in one location (Channamallikarjuna et al., 2010).

While transferring sheath blight resistance QTLs, notably, one line (Pusa 1604-05-3-5) possessing single QTL qSBR11-1 showed comparable disease reaction score as that of the donor parent, Tetep while Pusa1604-05- 45-1 possessing two and Pusa1604-0543-1 with three ShB resistance QTLs, showed moderate resistance only (Singh et al., 2015). This could be attributed to several reasons such as QTL-marker recombination (Moreau et al., 1998), QTL-background interactions (Wang et al., 2009; Chen et al., 2014), presence of un-known QTLs in the improved lines derived from donor (Tinker and Mather 1995) and/due to the competitive effectiveness of qSBR11-1 than the other two QTLs (Pandian et al., 2012). Further, disease resistance variations among the lines positive for all QTLs, can be attributed to epistatic effects and QTL-background interaction, a well-recognized component of natural genetic variation (Malmberg and Mauricio 2005). In our study, after validation of the donor parent Tetep for single major QTL (qSBR11-1) using tightly linked peakmarker (RM 224), introgression of QTL (qSBR11-1) was carried out into Swarna sub-1 by marker assisted backcross breeding.

The marker assisted backcross breeding QTLs has improved the resistance to sheath blight in all theimproved backcross derived lines while maintaining the quantitative and qualitative traits are almost similar with Swarna sub-1. This observation was similar to the resistance reaction reported against blast and sheath blightamong the MAS improved lines of Pusa Basmati 1 (Singh et al., 2012a) and to the resistance reaction reported against blast and sheath blight among MAS improved lines of Pusa 6B (Singh et al., 2015).

More resistance QTLs/genes are needed to be identified and introgressing them together into the elite cultivars ensures lifelong sheath blight resistance. Introgression of two or more resistance QTLs/genes should lead to more durable resistance in rice. In this study, introgressing QTL/genes conferring board spectrum and horizontal resistance through MAS were successfully conducted. Hence from the above finding it was concluded that the sheath blight resistance QTL/genes qSBR11-1 was successfully transferred into background of Swarna sub-1. This result is similar to previous reports on the successful utilization of MAB to transfer sheath blight resistance QTL/genes into Pusa 6B CMS line (Singh et al., 2015) and Improved Pusa Basmati-1 (Singh et al., 2012a). The introgressed lines obtained in our study can be used as genetic resources for sheath blight resistance in breeding programs that will be paving way for an environmental friendly means to achieve a better disease management. Moreover, the success will facilitate future efforts to transfer combinations of sheath blight resistance QTL/genes into other preferred rice cultivars.

\section{Conclusion}

The PCR amplification with RM224 marker for qSBR11-1 (on chromosome number 11) QTL showed polymorphism between Swarna sub-1 and Tetep, the varieties used as parent in the present study. Among $126 \mathrm{BC}_{1} \mathrm{~F}_{1}$ plants, only 27 plants showed the QTL/gene for resistance and remaining plants showed susceptible for disease due to absence of QTL/genes qSBR11-1. The number of spikelet's per panicle, test weight and grain yield were increased up to $3.45 \%, 0.62 \%$ and $0.72 \%$, respectively over recurrent parent Swarna sub1. The disease severity in selected $\mathrm{BC}_{2} \mathrm{~F}_{1}$ plants varied from 26.75 to 43.58 at 16 days after inoculation and areas under disease progress curve from 179.22 to 292.24. These broader spectrum and higher levels of resistance in the introgressed line might be due to interaction and / or complementation between the resistance genes. The introgressed lines obtained in our study can be used as genetic resources for sheath blight resistance in breeding programs that will be paving way for an environmental friendly means to achieve a better disease management. Moreover, the success will facilitate future efforts to transfer combinations of sheath blight resistance QTLs/genes into other preferred rice cultivars.

\section{REFERENCES}

Basavaraj, S. H., Singh, V. K., Singh, A, Singh, A, Singh, A, Yadav, S, Ellur, R. K., Singh, D., Gopalakrishnan, S., Nagarajan, M,, Mohapatra, T., Prabhu, K. V., and Singh, A. K. (2010). Marker-assisted improvement of bacterial blight resistance in parental lines of Pusa $\mathrm{RH} 10$, a superfine grain aromatic rice hybrid. Mol Breed, 26: 293-305

Bhaktavatsalam, G., Satyanarayana, K., Reddy, A. P. K., and John, V. T. (1978). Evaluation of sheath blight resistance in rice. International Rice Research Newsletter, 3: $9-10$

Chahal, S. S., Sokhi, S. S., and Ratan, G. S. (2003). Investigation on sheath blight of rice in Punjab. Indian Phytopathol, 56: 22-26

Channamallikarjuna, V., Sonah, H., Prasad, M., Rao, G. J. N., Chand, S., Upreti, H. C., Singh, N. K., and Sharma, T. R. (2010). Identification of major quantitative trait loci qSBR11-1 for sheath blight resistance in rice. $\mathrm{Mol}$ Breed, 25: 155-166

Chen, Z. X., Zhang, Y. F., Feng, F., Feng, M. H., Jiang, W., Ma, Y. Y., Pan, C. H, Hua, H. L., Li, G. S., Pan, X. B., and Zuo, S. M. (2014). Improvement of japonica rice resistance to sheath blight by pyramiding $q S B-9 T Q$ and qSB-7TQ. Field Crops Research, 161: 118-127 
Collard, B. C. Y., and Mackill, D. J. (2008). Marker-assisted selection: an approach for precision plant breeding in the twenty-first century. Phil Trans $R$ Soc B, 363:557572

Ghritlahre, S. K., Rao, M., Singh, V., Singh, V.K., Loitongbam, B., Yadav, S. K., Zaidi, N. W, Singh, U. S., and Singh, P. K. (2016). Inheritance of sheath blight disease resistance in submergence rice (Oryza sativa L.), International Journal of Agriculture, Environment and Biotechnology, 9(4): 507-512

Gopalakrishnan, S., Sharma, R. K., Rajkumar, K. A., Joseph, M., Singh, V. P., Singh, A. K., Bhat, K. V., Singh, N. K., and Mohapatra, T. (2008). Integrating marker assisted background analysis with foreground selection for identification of superior bacterial blight resistant recombinants in Basmati rice. Plant Breed.,127: 131-139

IRRI. (2002). Standard evaluation system for rice (SES). International Rice Research Institute, Los Banos, Philippines, $\mathrm{p} 56$.

Jia, Y., Liu, G., Costanzo, S., Lee, S., and Dai, Y. (2009). Current progress on genetic interactions of rice with rice blast and sheath blight fungi. Front Agric China, 3: 231 $-239$

Joshi, M., Singh, P. K., Waza, S. A., Singh, V., Goswami, S., Pallavi, Singh, P. K., Zaidi N. W., and Singh, U. S. (2016). Establishing an association between molecular markers and sheath blight (Rhizoctonia solani Kuhn) resistance in rice. Plant Omics, 9(4): 281-288

Kumar, A., Dixit, S., and Henry, A. (2013). Marker-assisted introgressionof major QTLs for grain yield under drought in rice. In: Varshney RK, Tuberosa R (eds) Translational genomics for crop breeding, volume II: abiotic stress, yield and quality. Wiley, New York, Pp. 47-64

Kumar, M., Singh, V., Singh, N., and Vikram, P. (2008). Morphological and virulence characterization of Rhizoctonia solani causing sheath blight of rice. Environ Ecol, 26 (3): 1158-1166

Li, Z. K., Pinson, S. R. M., Marchetti, M. A., Stansel, J. W., and Park, W. D. (1995). Identification of quantitative trait loci (QTLs) for heading date and plant height in cultivated rice (Oryza sativa L.). Theor Appl Genet, 91: 374-381

Malmberg, R. L., and Mauricio, R. (2005). QTL-based evidence for the role of epistasis in evolution. Genet Res (Camb), 86: 89-95

Moreau, L., Charcosset, A., Hospital, F., and Gallais, A. (1998). Marker assisted selection efficiency in populations of finite size. Genetics, 148: 1353-1365

Pandian, R. T. P., Sharma, P., Singh, V. K., Singh, A., Ellur, R. K., Singh, A. K., and Singh, U. D. (2012). Validation of sheath blight resistance derived from Tetep in a Basmati variety and parental lines of rice hybrid. Indian Phytopathol, 65: 233-237

Prabhu, K. V., Somers, D. J., Rakow, G., and Gugel, R. K. (1998). Molecular markers linked to white rust resistance in mustard Brassica juncea. Theor Appl Genet, 97: 865-870

Savary, S., Castilla, N. P., Elazegui, F. A., McLaren, C. G., Ynalvez, M. A., and Teng, P. S., (1995). Direct and indirect effects of nitrogen supply and disease source structure on rice sheath blight spread. Phytopathology, 85: 959-965

Savary, S., Teng, P. S., Willocquet L., and Nutter, F. W. J. (2006). Quantification and modeling of crop losses: a review of purpose. Ann Rev Phytopathol., 44: 89-112

Singh, A., Singh, V. K., Singh, S. P., Ellur, R. K., Singh D., Bhowmick, K., Gopala Krishnan, S., Nagarajan, M., Vinod, K. K., Mohapatra, T., Prabhu, K. V., and Singh, A. K. (2012b). Marker aided improvement of Pusa1460 an elite Basmati rice for resistance to Blast diseases. AoB Plants pls, 029. doi:10.1093/aobpla/pls029.

Singh, A. K., Singh, V. K., Singh, A., Ellur, R. K., Pandian, R. T. P., Gopala Krishnan, S., Singh, U.D., Nagarajan, M., Vinod, K. K., and Prabhu, K. V. (2015). Introgression of multiple disease resistance into a maintainer of Basmati rice CMS line by marker assisted backcross breeding, Euphytica, 203: 97-107

Singh, V. K., Singh, A., Singh, S. P., Ellur, R. K., Choudhary, V., Sarkhel, S., Singh, D., Gopala Krishnan, S., Nagarajan, M., Vinod, K. K., Singh, U. D., Rathore, R., Prasanthi, S. K., Agrawal, P. K., Bhatt, J. C., Mohapatra, T., Prabhu, K. V., and Singh, A. K. (2012a). Incorporation of blast resistance into "PRR78", an elite Basmati rice restorer line, through marker assisted backcross breeding. Field Crop Res., 128: $8-16$

Srinivasachary, L., Willocquet, L., and Savary, S., (2011). Resistance to rice sheath blight (Rhizoctonia solani Kuhn) [teleomorph: Thanatephoru scucumeris (A. B. Frank) Donk.] disease: current status and perspectives. Euphytica, 178: 1-22

Tanksley, S. D., Young, N. D., Paterson, A. H. and Bonierbale, M. W. (1989). RFLP mapping in plant breeding: new tools for an old science. Biotechnology, 7: 257-264

Tinker, N. A. and Mather, D. E. (1995). Methods for QTL analysis with progeny replicated in multiple environments. J Agric Genom., 1: 1-16

Wang, C., Wen, G., Lin, X., Liu, X. and Zhang, D. (2009). Identification and fine mapping of the new bacterial blight gene, Xa31(t) in rice, Eur. J. Plant Pathol., 123: 235-240

Wang, Y., Pinson, S. R. M., Fjellstrom, R. G. and Tabien, R. E. (2012). Phenotypic gain from introgression of two QTL, qSB9-2 and qSB12-1 for rice sheath blight resistance. Molecular Breeding, 30: 293-303

Xu, Q., Yuan, X. P., Yu, H. Y., Wang, Y. P., Tang, S. X. and Wei, X. H. (2010). Mapping quantitative trait loci for sheath blight resistance in rice using double haploid population. Plant Breed, 130: 404-406

Zuo, S. M., Zhang, Y. F., Chen, Z. X., Chen, X J. and Pan, X. B. (2010). Current progress on genetics and breeding in resistance to rice sheath blight. Sci Sin Vitae, 40(11): 1014-1023

Zuo, S., Zhang, L., Wang, H., Yin, Y., Zhang, Y., Chen, Z., Ma, Y. and Pan, X. (2008). Prospect of the QTL-qSB9Tq utilized in molecular breeding program of japonica rice against sheath blight. J Genet Genom., 35: 499-505 